\title{
Strategic Analysis of Advertisement Tools Affecting Consumer Buying Behaviour
}

\author{
${ }^{1}$ Ms. Mansi Kapoor, ${ }^{2}$ Ms. Suman Si, ${ }^{3}$ Ms. Sangeeta Gupta \\ ${ }^{1}$ Assistant Professor, Delhi College of Arts and Commerce, University of Delhi, Delhi, India \\ ${ }^{2}$ Assistant Professor, PGDAV College, University of Delhi, Delhi, India \\ ${ }^{3}$ Assistant Professor, Delhi College of Arts and Commerce, University of Delhi, Delhi, India
}

\begin{abstract}
The paper provides an understanding of how consumer's responses can vary as a function of advertising context. The paper gives an insight about the interface with ads and its tools at large and facilitating a better role in terms of market awareness of various advertisement and its tools by engaging in development of newer strategies for a much more satisfactory level of performance. Such advertisement tools help the marketers to survive in the Indian market in future.

The paper analyses how a celebrity endorser helps to perceive as a winning formula for product marketing and brand building and how sensitivity in humour helps to make the product more memorable. The continuous challenge in advertising is to find the human truths and connect them with the product to create engaging communication on an emotional front thereby generating a sense of belonging towards the company's product for an effective purchase. Products have to put a lot of effort to develop a mechanism by which they can really estimate the overall impact of advertisement on the community in general and product in particular. The study uses the primary as well the secondary data to assess how advertisement leads to purchase and act as a source of information and the impact of the most important aspects of advertisement in relation to celebrity endorsement, sensitivity of humour, emotions, ethics, music and Nationality of the advertisement context.
\end{abstract}

Keywords: advertising, advertisement tools, celebrity endorsement, consumer behaviour, ethics in advertising

\section{Introduction}

It is widely held by both practitioners and academics that advertising works best by delivering a unique persuasive informational message. Rosser Reeves assertion that 'Advertising is the art of getting a unique selling proposition into the heads of the most people at the lowest possible cost' (1961: 121) is mirrored nearly 40 years later by Duncan \& Moriarty in Advertising Age, who describe advertising as 'one-way communication: creating and sending messages' (1999: 44). Jones describes advertising as an activity which 'increases people's knowledge and changes people's attitudes' (1990: 237).

Advertising has become so integral part of our life \& society that we cannot imagine any event, newspaper, magazine, TV serial, Cinema etc. without advertising. Advertising is a vital marketing tool as well as powerful communication medium. The basic objective of any advertisement is to stimulate sales, direct or indirect by trying to make tall claims about product performance.

The term advertising is derived from the original Latin word 'advertere' which means 'to turn' the attention. Every piece of advertising turns the attention of the reader or the listeners or the viewers or the onlookers towards a product or a service or an idea. According to the New Encyclopaedia Britannica, "Advertising is a form of communication intended to promote the sale of a product or service to influence the public opinion to gain political support or to advance a particular cause".

Advertising can be utilized for creating awareness and promoting one of the services or for services of all the departments. A thorough analysis is required to decide about the objectives of a particular advertising campaign. The objectives can vary from providing information, creating awareness, building brand or utilizing the services and product to optimal capacity. Advertising objective has to be decided keeping in mind targeted clientele and also service to be promoted. In case of a screening package, the target clientele is decided then the objective becomes crystalline to increase the utilization of screening package. The desired response from advertising campaign has to be also defined such as increase in the number of customers utilizing that service, increase in the number of customer inquiries exhibiting an increase in the awareness, etc

Advertising budget is a very crucial issue that should be addressed at priority because an advertising campaign cannot be planned without proper input of funds. . The success of an advertising campaign depends on the factor that it communicates the desired message to the community and does not cross the legal, ethical and moral limitations. A more appropriate approach can be using a demographic-service dimension grid. 
For an effective advertising impact, products have to put a lot of effort to develop a mechanism by which they can really estimate the overall impact of advertisement on the community in general and product in particular.

\section{Objectives}

1. To formulate a comprehensive research idea to study the pattern of advertisement tools.

2. To understand how various advertisement tools have an impact on the consumption pattern of the consumer.

3. To understand why, what tools must be used to make the best advertisement.

\section{Literature Review}

Advertising is, according to Belch and Belch (2004), any paid form of nonpersonal communication about an organization, product, service, or idea by an identified sponsor. Wells, Burnett, and Moriarty (2000) claim that advertising is nonpersonal since it is a form of mass communication and defines advertising as nonpersonal communication from an identified sponsor using mass media to persuade or influence an audience. Belch and Belch (2004) suggest that advertising is the best known promotional tool since it is persuasive. It is also a very important tool for companies whose products and services are aiming to satisfy mass consumer markets.

Advertising is according to Tellis (2004) an enormous industry and the growth in expenditures indicates that the importance of advertising is not declining. The total expenditures in the United States on all media advertising in the 2002 were nearly $\$ 240$ billion (Armstrong \& Kotler, 2005, Belch \& Belch, 2004, Tellis, 2004). This could be compared to the total expenditure of $\$ 53$ billion in 1980. Promotional expenditures in international markets have grown as well. Advertising expenditures outside the United States increased from $\$ 55$ billion in 1980 to nearly $\$ 214$ billion by 2002 . However, there is no nation that could be compared to the U.S. where companies collectively are spending more than $\$ 1500$ per capita a year on every man, woman, and child in the country - nearly 50 percent more per capita than in any other nation (Belch \& Belch, 2004).

Advertising can be, in some cases be the sole reason for the growth of the company or the product. The effectiveness of advertising depends on the selection of right media for conveying the said message to the target audience.

Smith and Taylor (2002) emphasize the need for advertisers to think outside the box and engage in a more dynamic and creative methods of advertising via direct mail, telesales, Internet, television Radio etc. Tellis (2004) emphasize that only a few advertising campaigns are successful and only a few ads are able to reach over the level of noise and seize attention. This could be explained by inattention to advertising, resistance to persuasion, miscomprehension of ad message, and imitation of effective techniques.

Analysis of the consumer and advertising spend data in this year's online Outlook 2013-2017, shows that the consumer demand for entertainment and media (E\&M) experiences, fuelled largely by the adoption of broadband and connected devices, will continue to grow and we expect this growth to follow a similar trend to GDP development across the forecast period 2013-2017. However, given the shift towards digital mediatypically lower priced than its physical counterpart-we anticipate spend to lag behind GDP growth. The global E\&M market will grow at a CAGR of 5.6\% over the next five years, generating revenues in 2017 of US\$2.2tn, up from US\$1.6tn in 2012. Within this overall figure, all three sub-categories-advertising, consumer spend on content, and access - will continue to grow, but at varying rates.

\section{Research Methodology}

The study is based on primary data as well as secondary sources. In case of primary data, a structured questionnaire was made \& personal interview were taken of 150 respondents, within the geographical region of Delhi in order to gauge the market opinion accurately with regard to the impact of celebrity endorsement, emotions, nationality, music and ethics which helps to create brand awareness and lead to the purchase of a product. The secondary data was gathered with the help of various magazines, newspapers, journals, brochures and also through the internet. The statistical techniques such a Pi-chart and percentages were used in analysing and interpreting the data.

\section{Does "Celebrity Endorsement" Sell In Advertising?}

ICICI bank recently endorsed Amitabh Bachchan for their new Banking services which allow the customers to stay at home and enjoy thereby open a bank account on a click of a tablet. For Cars, a jaunty hero like Shahrukh Khan for Hyundai i10 ad or Anushka Sharma for Scooty Pep Ad was taken to promote two and four vehicles respectively.

And a long list in promoting cosmetics by Kareena Kapoor and Amitabh Bachchan for cold cream ads. 
Accessories like watches, clothing, and jewelleries get some of the top shot film stars and celebrities to sell their products like M S Dhoni and Asin for promoting Big Bazar clothing. Aishwarya Rai for Longines watches and Shahrukh Khan for Tag Heuer, Bipasha basu, Sonakshi Sinha, Preity Zinta for promoting various onscreen and print ads for jewelleries.

The film celebrity (who, with the sports celebrity, just about covers the list) is the new mediator of this publicity: if it was just the product that was once stealing your love of yourself, it is now that product and Aishwarya Rai, or Shah Rukh Khan, or M S Dhoni, or Amitabh, or someone else like that.

The managers of consumerism says they work, if the celebrity is used consistently with a product, when there is a fit between the two, when the commodity is further fetishes by the association with the film star. What is fascinating about ad-culture is the narrative structure it adopts, the way in which advertisements have come to be whole spectacles in themselves.

Around the world, television advertisers use celebrities or stars in a bid to win consumer's attention, interest, and favourable attitudes toward their brands. Advertisers have employed famous athletes, actors, musicians, and even political figures. Does it really work? Sometimes it does successful celebrity campaigns are famous. Sometimes it doesn't. Few years back, testimonials by celebrities were quoted below average in their ability to change brand preference. Viewers guess that the celebrity has been bought, and they are right. Viewers have a way of remembering the celebrity but forgetting the product.

Another finding from the research is that celebrity ads often achieve lower ratings not only for believability, but for relevance and differentiation as well. Relevance and credibility depend on how the message and the product fit with the star's persona, and how these elements are related in the ad. In the simplest form, the ad may associate the brand with a star's.

As regard to endorser impact, when we think 'Brand Amul', the chubby girl in a polka dot frock flashes across our mind. 'Chintamani', mascot of ICICI Prudential Life Insurance is also quite a hit with the consumers. The use of celebrity endorsers in marketing enjoys high popularity, largely because they may exert a positive impact on brand image.

Celebrity endorsement has been established as one of the most popular tools of advertising in recent time. It has become a trend and perceived as a winning formula for product marketing and brand building. It is easy to choose a celebrity but it is tough to establish a strong association between the product and the endorser. The study shows that consumers report higher self-brand connections for brands with images that are consistent with the image of a celebrity that they aspire to be like, particularly in the case when the image of the celebrity and the brand match. Study also examines how self-brand connections are formed. Celebrity endorsement effects are moderated by brand symbolism, such that brands that communicate something about the user yield stronger effects than brands that do not. In the case of inspirational celebrities, the positive effect of image congruency is stronger for those brands that are perceived to communicate something symbolic about the brand's user compared to those brands that do not. This finding is an important demonstration that consumers are motivated by their self-need to utilize brand associations derived from celebrity endorsement in a contingent fashion to construct and present their self-identities.

\section{Does "Humour" Sell In Advertising?}

The media industry is booming. There has been a steep rise in the number of television channels, which has meant a lot more programming and many more advertisements vying for the consumer's attention. The question many advertising professionals are pondering over is how will your ad create an impact amidst such clutter? What must you keep in mind while striving to make an advertisement that works?

While this can be done in a number of ways, like using emotions to move the viewer or by tickling his funny bone, it is the use of humor that remains one of the most preferred methods of making an ad memorable. Humour is the best way to cut clutter. If your ad manages to bring a smile to the viewer's face, half the job is done. It ensures instant brand recall," says Abhijeet Awasthi, O\&M (their campaigns include Hutch, Cadbury's Dairy Milk, Fevicol, and Fevikwik). Humour is a very powerful tool. It is one of the strongest hooks. It is best suited for products that a consumer would buy instinctively; a chewing gum or a soft drink. These brands won't be persuasive but they will attempt to make an impact by making the viewer laugh. If the consumer needs to make an important decision while selecting your brand, for example, a car or an insurance policy, then humour, if at all it is used, must be imbibed with the message. A good example would be 'Fevicol Marine', its waterproof adhesive. The ad reiterates Fevicol Marine's strong bond in water with the tagline 'Wahi mazboot jod, paani mein bhi'.

Advertising, like any other field, does not have any absolute thumb rules; in fact, the rules of the game are contextual. In other words, the strategy you employ while creating an ad or a campaign will vary from product to product, depending on the objective of your campaign and the kind of audience you wish to target. Many of the most memorable ad campaigns around tend to be funny. Advertisers use this strategy to attract 
customers to their product. The key to funny advertising is assuring the humor is appropriate to both product and customer.

Many of the most memorable ad campaigns around tend to be funny. Advertisers use this strategy to attract customers to their product. Audiences like to be entertained, but not pitched. People will pay more attention to a humorous commercial than a factual or serious one, opening themselves up to be influenced. The key to funny advertising is assuring the humor is appropriate to both product and customer. The balance between funny and obnoxious can often be delicate; and a marketer must be certain the positive effects outweigh the negative before an advertisement can be introduced. Humorous campaigns are often expensive because they have to be constantly changed. Advertisers must remember that while making the customer laugh, they have to keep things interesting, because old jokes die along with their products.

\section{Do "Emotions" Sell In Advertising?}

Tata Salt came up with an emotional wave with its advertising campaign where the brand's communication used a distinctive take to depict the purity of salt (kharapan) in simple acts of honesty. It also attempts to elevate the brand to the status of a national icon "desh ka namak" (the country's salt). With this positioning, Tata Chemicals, the manufacturers of Tata Salt, hopes to break the brand clutter caused by recent entrants in the salt market. The recent AD campaign by TATA tea "Jaago Re" instigated the youth to vote in the current elections and choose a right leader for the country and also empower women to participate in elections. The pioneer in India's branded-salt industry, Tata Salt has held the number one position in the country since its launch in 1983. It has a 37 per cent share of the branded-salt market and a 17 per cent share of the total salt market.

The first job of any company is to show people how good they will feel when they buy what you offer. Whatever you offer, remember that emotions create the desire and logic backs it up. You need both, but if all you offer is logic, it will be a tough sale. It isn't always easy. Sometimes you have to uncover hidden benefits that appeal to emotions people don't necessarily want to talk about.

You are what you look is a strong universal truth. And it has been used over years, interestingly across product categories as diverse as detergents and credit cards to make connects with consumers. Rin used it a few years ago in jewellery commercial where a non-Rin woman was not allowed into the store and not treated well as a Rin woman.

And American Express used the same to make the point, a passport to get any one into anywhere however you look. So a couple, colored by Holi celebrations, are allowed into a five star hotel on flashing the card. Finally, Cadbury Dairy Milk has been built in the last decade by tapping into the universal truth that there is a child in all of us that never dies and celebrating relations through their tagline "kuch mithas ho jaye".

The continuous challenge in advertising is to find these human truths and connect them with the product to create engaging communication. They could come out of detailed yet sensitive research, interrogating the consumer on the product, his interaction with the category and his emotions connected with it. There is however, neither any known formula for success in advertising nor for unearthing such human truths or insights. It's all about trying to tell a product story in a refreshing new way with a truth that strikes a chord with the viewer.

\section{Does "Nationality" Sell In Advertising?}

Nationally produced television advertisements in particular may be considered among the most highly polished cultural artifacts ever created. Nationality is use for giving home feeling to target audience. It shows that we are yours only. Pepsi has adopted this strategy now. Hero Honda is most selling scooter in India. Hero Honda gave Hamra Bajaj slogan and its recent ad claiming "desh ki dhadkan". Recently, Salman Khan promoted Rotomac pens to promote education with the tagline "India ki nayi pehchan".

\section{Importance of "Music" In Advertising}

Second-for-second basis, advertising music is perhaps the most meticulously crafted and most frettedabout music in history. But it is the overt knowledge of objectives and the consequent desire to control and handle the tools of musical meaning which make advertising such a compelling object of musical study. Of the estimated sixty billion broadcast advertising hours encountered by India each year, approximately three-quarters employ music in some manner. Music can serve the overall promotional goals in one or more of several capacities. For this purpose, six basic ways were identified in which music can contribute to an effective broadcast advertisement which in terms of entertainment, structure, continuity, memorability, lyrical language, targeting, and authority establishment. 


\section{X. $\quad$ Ethics In Advertising}

The field of advertising is extremely broad and diverse. In general terms, of course, an advertisement is simply a public notice meant to convey information and invite patronage or some other response. As that suggests, advertising has two basic purposes, to inform and to persuade, and while these purposes are distinguishable, both being present simultaneously.

Advertisers are selective about the values and attitudes to be fostered and encouraged, promoting some while ignoring others. This selectivity gives the lie to the notion that advertising does no more than reflect the surrounding culture. For example, the absence from advertising of certain racial and ethnic groups in some multi-racial or multi-ethnic societies can help to create problems of image and identity, especially among those neglected, and the almost inevitable impression in commercial advertising that an abundance of possessions leads to happiness and fulfillment can be both misleading and frustrating.

Advertising also has an indirect but powerful impact on society through its influence on media. Many publications and broadcasting operations depend on advertising revenue for survival. This often is true of religious media as well as commercial media. For their part, advertisers naturally seek to reach audiences; and the media, striving to deliver audiences to advertisers, must shape their content so to attract audiences of the size and demographic composition sought. This economic dependency of media and the power it confers upon advertisers carries with it serious responsibilities for both.

\section{The Benefits Of Advertising}

Advertising can play an important role in the process by which an economic system guided by moral norms and responsive to the common good contributes to human development. In such a system, advertising can be a useful tool for sustaining honest and ethically responsible competition that contributes to economic growth in the service of authentic human development. Advertising does this, among other ways, by informing people about the availability of rationally desirable new products and services and improvements in existing ones, helping them to make informed, prudent consumer decisions, contributing to efficiency and the lowering of prices, and stimulating economic progress through the expansion of business and trade.

Political advertising can make a contribution to democracy analogous to its contribution to economic well being in a market system guided by moral norms. As free and responsible media in a democratic system help to counteract tendencies toward the monopolization of power on the part of oligarchies and special interests, so political advertising can make its contribution by informing people about the ideas and policy proposals of parties and candidates, including new candidates not previously known to the public.

Culturally, the impact of advertising depends on the media for revenue; advertisers have an opportunity to exert a positive influence on decisions about media content. They do this by supporting material of excellent intellectual, aesthetic and moral quality presented with the public interest in view, and particularly by encouraging and making possible media presentations which are oriented to minorities whose needs might otherwise go unserved. Moreover, advertising can itself contribute to the betterment of society by uplifting and inspiring people and motivating them to act in ways that benefit themselves and others. Advertising can brighten lives simply by being witty, tasteful and entertaining. Some advertisements are instances of popular art, with a vivacity and elegance of their own.

Morally \& religiously, in many cases, benevolent social institutions, including those of a religious nature, use advertising to communicate their messages-messages of faith, of patriotism, of tolerance, compassion and neighborly service, of charity toward the needy, messages concerning health and education, constructive and helpful messages that educate and motivate people in a variety of beneficial ways.

\section{Data Analysis \& Interpretation}

\section{(1) The purpose of advertising}

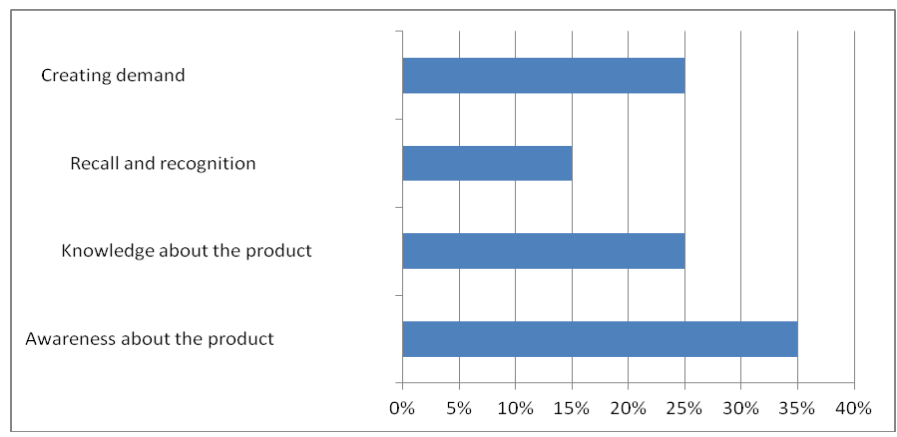


(2) Audience of advertisements

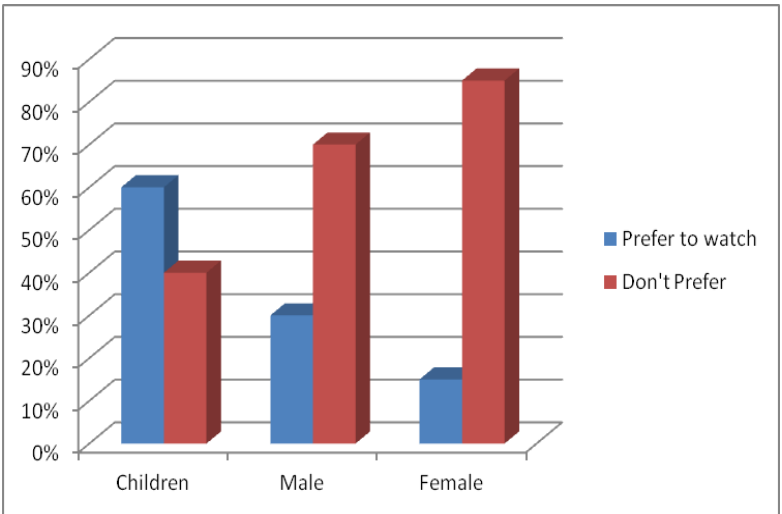

(3) Advertisements as a source of information

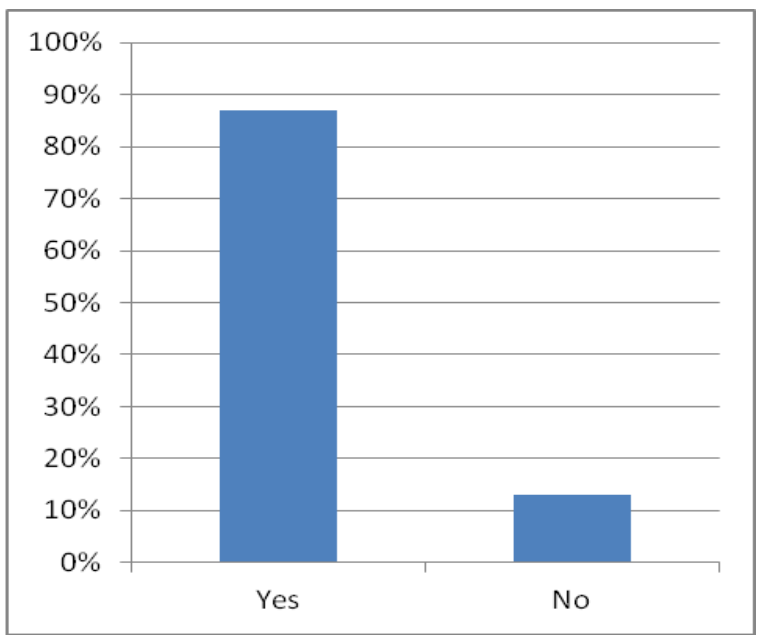

(4) Advertisements are followed

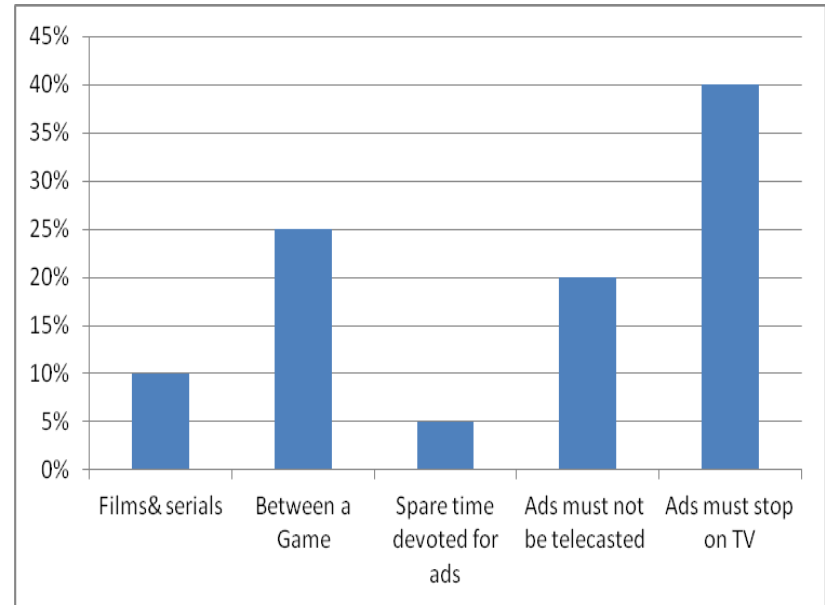


(5) Advertisement leads to purchase

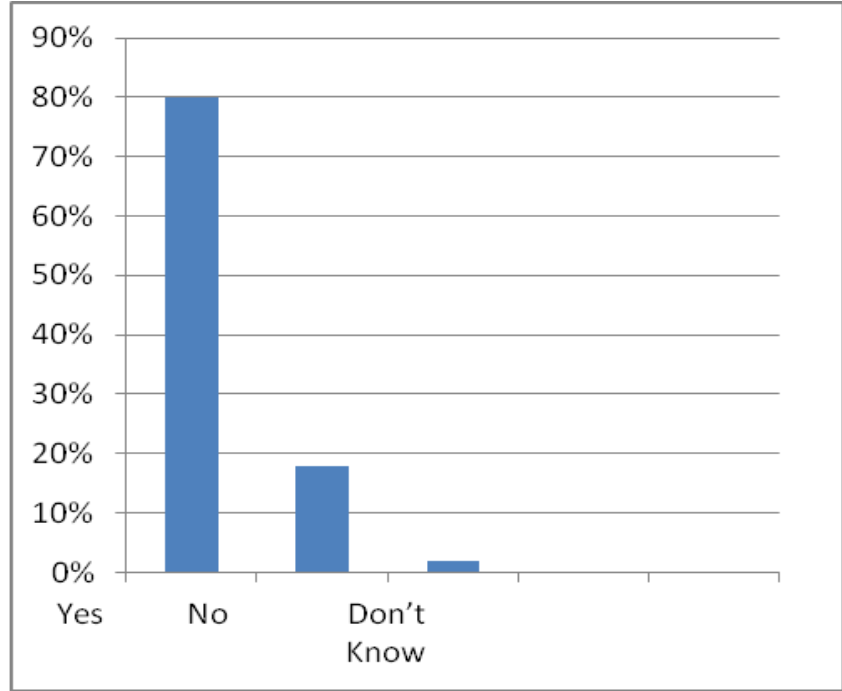

(6) Impacts of celebrities in advertisements

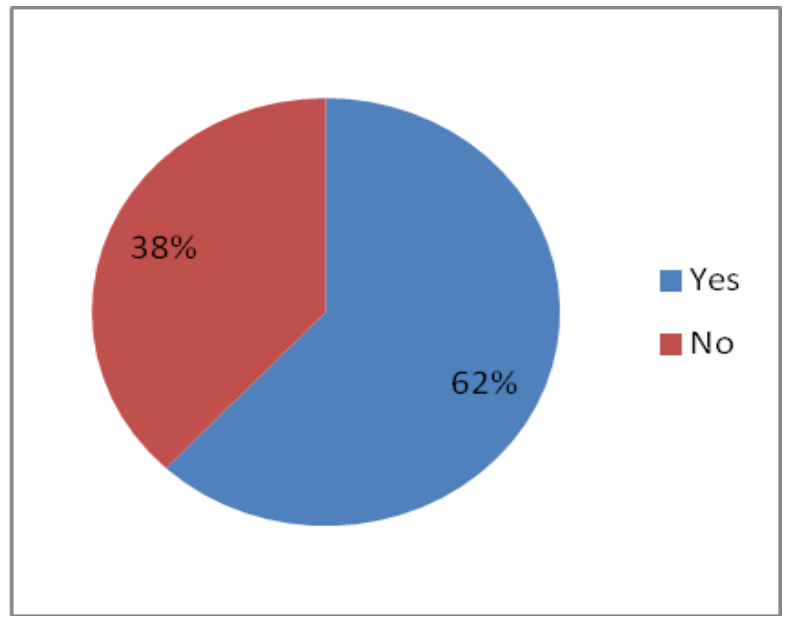

(7) Sports stars, models or film stars:

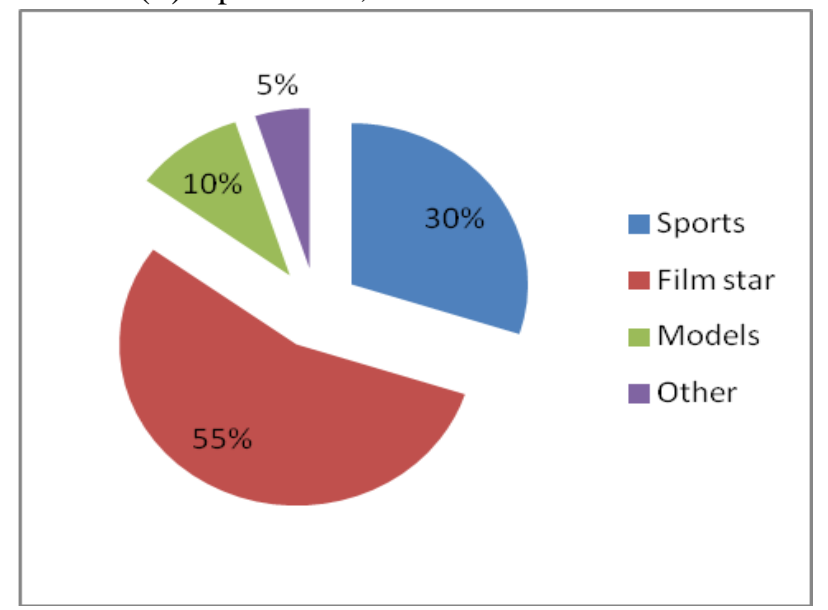


(8) Effectiveness of "Nationality" in advertisement

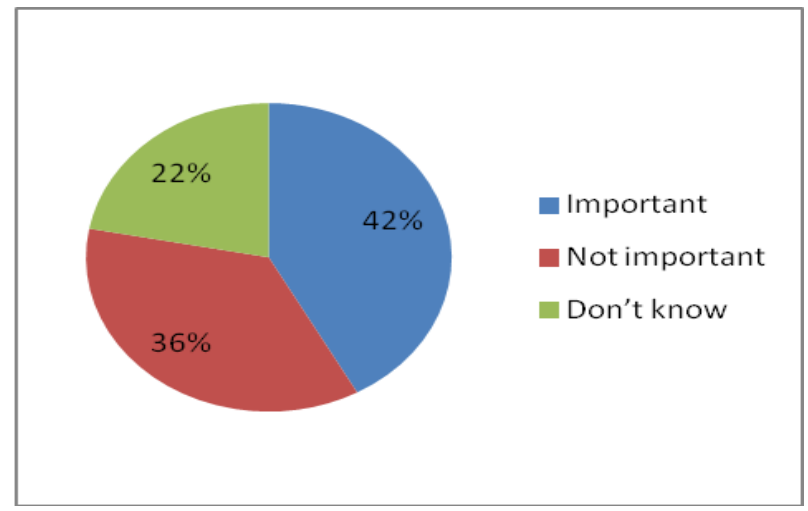

(9) Importance of "humour" in advertisement

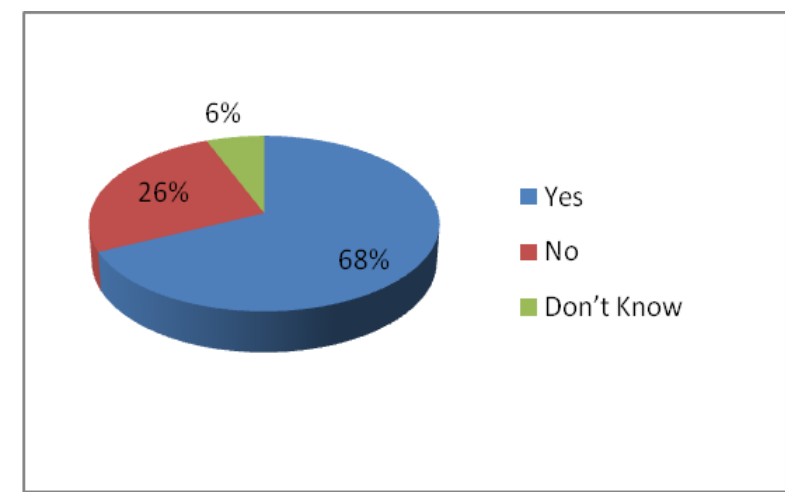

(10) Ethics in advertisements: do they work?

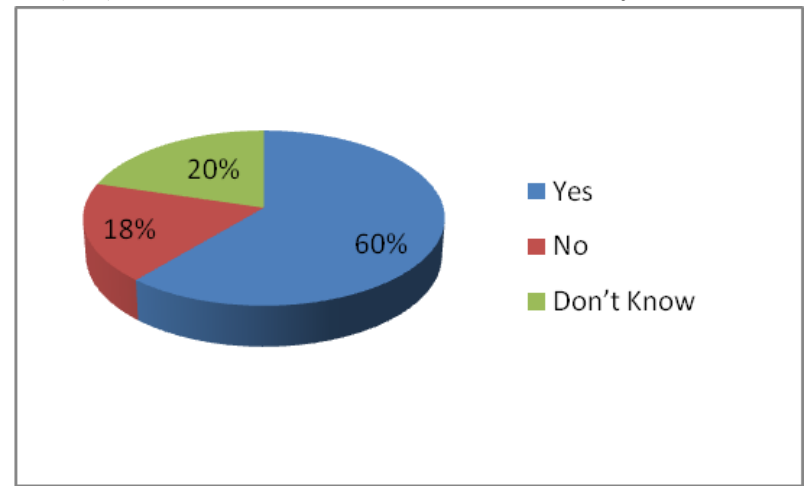

(11) Emotions in advertisements

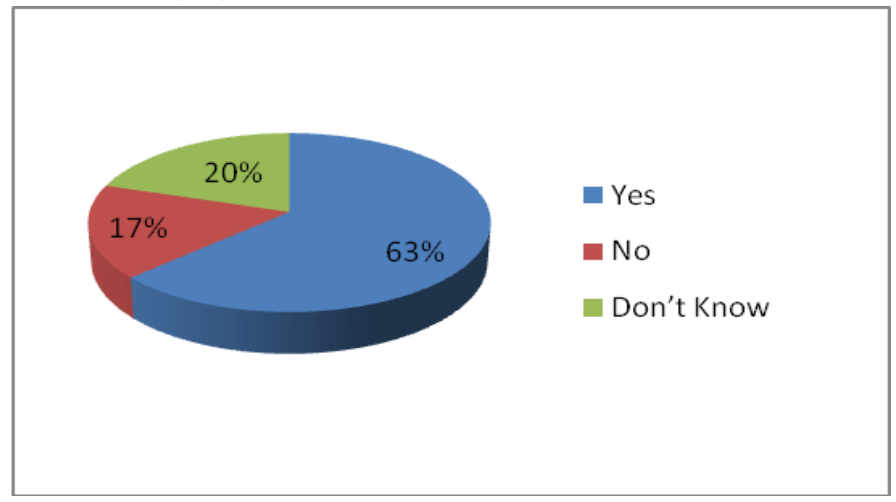


(12)

Best media vehicle

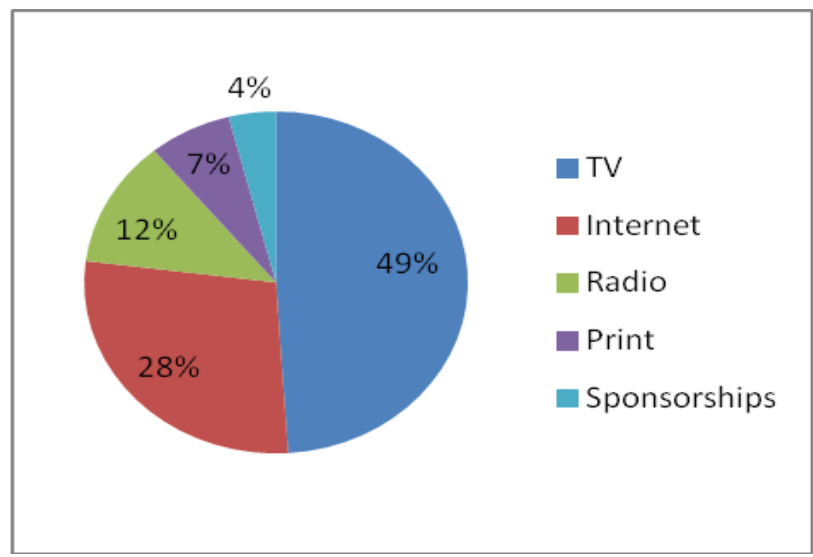

\section{Conclusions}

As per the analysis, the main purpose of advertising is considered to create awareness about the product followed by the knowledge of the existing product, creating its demand and recall/recognition of the product. $35 \%$ of the people watch an advertisement for becoming aware about a new product in the market, $25 \%$ of the people feel that advertisement is for giving knowledge/ information about an existing product. Another $25 \%$ feel that advertisement is a tool for creating demand in market. Whereas, the least number of people think that it is meant to facilitate recall and recognition.

While $60 \%$ children form the largest audience for advertisements, $70 \%$ adults think of it as a waste of time. Among adults, the numbers of males who like watching advertisements are more than the number of females, the ratio being $30 \%$ and $15 \%$ respectively. $85 \%$ females usually do not prefer to watch advertisements and do other work while advertisements are running. $85 \%$ of the population thinks that advertisement is a source of information while $15 \%$ think otherwise.

As per the data, $10 \%$ of the advertisements are followed between films and serials, $25 \%$ between games while devoting $5 \%$ time for ads. $20 \%$ of the population believe that ads must not be telecasted while $40 \%$ of them believe that ads must not be shown at all on TV. $80 \%$ people get influenced by ads and purchase products, while only $18 \%$ need not do intensive research before buying anything. $62 \%$ people feel that using celebrities in advertisements is fruitful because it is easy to remember the advertisement if celebrity is there as they act and serve as a style statement while $38 \%$ think that using celebrity in an advertisement is a waste of money.

From the survey, it is clear that $55 \%$ of the people prefer film celebrities, while $30 \%$ prefer to see spots stars and $10 \%$ like models. The rest of the 5\% believe that even laymen can act in advertisements. $42 \%$ believe that Nationality is an important part of advertisement content while 36\% believe it to be unimportant. $68 \%$ says that Humour is a very important aspect of advertising, while $26 \%$ considered it to be unimportant. Ethics are considered to be another important factor in advertisement which $60 \%$ of the people believe is to be while $18 \%$ thinks it otherwise. Emotions in advertisement is being cited another important factor by $63 \%$ of the people while $17 \%$ don't feel about it. In terms of the best media vehicle, $49 \%$ believe that best advertisement medium is $\mathrm{TV}$, because of its wider reach, being entertaining, more efficient \& effective making the advertisements easier to remember, followed by $28 \%$ to Internet because of the increasing internet users these days while $12 \%$ give importance to radio, $7 \%$ to print and $4 \%$ to sponsorships.

\section{Recommendations}

Advertisement must be according to product and its impact on target audience. Advertisement that bank on fear and negative appeal like neighbor's envy, jealousy, feud between daughter-in-law and mother-inlaw etc. should not be made considering the value system of our society. The ads that suggest the use of preserved food items without a slightest mention of the fact that many of these preservatives have been proved to have carcinogenic effect must be considered by the company promoting their product. The ads should not be deceptive and must reveal the true nature of the product like the ads of cosmetics, which say nothing about the long-term effects of regular usage of their products, or the ads of the educational institution that wrongly claim to give 100 percent placement to its students. The ads that target the vulnerability of the children and adolescents create role models whom the kids are expected to emulate and, thus, shape their dreams and aspirations in an unbecoming way must not mislead them. Advertising is not always about making great-looking, intelligent ads. At the end of the day, you are being paid by a client to increase his product's sales so that ought to be your primary concern. One must watch the advertisements that come on the tube and analyse them to see whether the commercial convinced you to buy the 
product or not. The more advertisements you watch with a keen eye, the more one's knowledge is increased. Society should be the key inspiration for the advertisers, one need to understand whether the campaign is introducing the brand in the market, or building its image, or just informing the viewer about a particular offer.

Building the campaign depends on the target audience. The style of the commercials, the language used, the situation depicted, and the kind of humour used, if any, all these factors depend on the target audience. Advertising is all about role-playing. One has to put himself in the shoes of the specific group of consumers one intends to target. Make the viewer identify with what you are saying. Remember the most important rule of advertising - there are no rules.

\section{References}

[1] Duncan, T. \& Moriarty, S. (1999) Brand relationships key to agency of the future, Advertising Age, Vol. 70, Issue 10: 44

[2] Jones, J.P. (1990) Advertising: Strong Force or Weak Force? Two Views an Ocean Apart. International Journal of Advertising Vol. 9, Issue 3: 233-246

[3] Jones, J.P. (2002) The Ultimate Secrets of Advertising, Sage Publications, Thousand Oaks, Ca http://www.pwc.in/industries/entertainment-and-media.jhtml

[4] http://adage.com/article/cmo-strategy/marketing-celebrity-endorsements-push-product/146023/

[5] Aaker, David A., Douglas M Stayman, and Michael R. Hagerty (1986), "Warmth in Advertising: Measurement, Impact, and Sequence Effects," Journal of Consumer Research, 12 (March), 365381.

[6] Chook, Paul H. (1985), "A Continuing Study of Magazine Environment, Frequency, and Advertising Performance," Journal of Advertising Research, 25 (4), 23-33.

[7] Goldberg, Marvin E. and Gerald J. Gorn (1987), "Happy and Sad TV Programs: How They Affect Reactions to Commercials," Journal of Consumer Research, 14 (December), 387-403.

[8] Helson, H. (1964), Adaptation Level Theory, New York: Harper \& Row.

[9] Herr, Paul M. (1989), "Priming Price: Prior Knowledge and Context Effects," Journal of Consumer Research, 16 (June), 67-75.

[10] Meyers-Levy, Joan (1-989), "Priming Effects on Product Judgments: A Hemispheric Interpretation," Journal of Consumer Research, 16 (June), 76-86.

[11] Schultz, D. E. (1979), "Media Research Users Want," Journal of Advertising Research, 19 (December), 13-17.

[12] Shaver, P., J. Schwartz, D. Kirson, and C. O'Connor (1987), "Emotion Knowledge: Further Exploration of a Prototype Approach," Journal of Personality and Social Psychology, 52 (6), 1061-1086.

[13] Soldow, Gary F. and Victor Principe (1981), "Response to Commercials as a Function of Program Context," Journal of Advertising Research, 21 (2), 59-65.

[14] www.pwc.in/industries/entertainment-and-media.html

[15] https://www.experience.com/alumnus/article?channel_id=advertising_marketing_pr\&source_page=editors_picks\&article_id=article _1128619972620

[16] Gerard J. Tellis, Marshall School of Business, University of Southern California, Journal of advertising research, June 2009

[17] Elizabeth Marting, New Products, New Profits (New York: American Management Association, 1964)

[18] Roger H. Bolin, cited in Russel H. Colley, Defining Advertising Goals for Measured Advertising Results (New York: Association of National Advertisers, 1961), Foreword.) Journal of Marketing. Vol. 33, 1969). 